\title{
Erratum to: The JBEl quantitative metabolic modeling library (jQMM): a python library for modeling microbial metabolism
}

Garrett W. Birkel ${ }^{1,2,8}$, Amit Ghosh ${ }^{1,2,6}$, Vinay S. Kumar ${ }^{1,2}$, Daniel Weaver ${ }^{1,2}$, David Ando ${ }^{1,2}$, Tyler W. H. Backman ${ }^{1,2,8}$, Adam P. Arkin ${ }^{1,4,5}$, Jay D. Keasling ${ }^{1,2,3,4,7}$ and Héctor García Martín 1,2,8,9*

\section{Erratum}

Following publication of this article [1], it has come to our attention that an incomplete version of Fig. 7 was included in this article. The complete figure is shown below with the missing text included to the left of the chart.

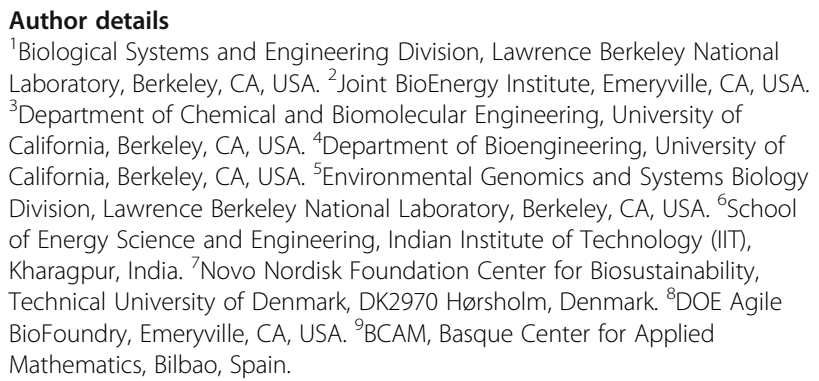

Received: 10 April 2017 Accepted: 11 April 2017

Published online: 18 April 2017

\section{Reference}

1. Birkel G, Ghosh A, Kumar V, Weaver D, Ando D, Backman T, et al.

The JBEl quantitative metabolic modeling library (jQMM): a python library for modeling microbial metabolism. BMC Bioinformatics. 2017;18:1. doi:10.1186/s12859-017-1615-y.

\footnotetext{
* Correspondence: hgmartin@|bl.gov

${ }^{1}$ Biological Systems and Engineering Division, Lawrence Berkeley National Laboratory, Berkeley, CA, USA

${ }^{2}$ Joint BioEnergy Institute, Emeryville, CA, USA
} 
Birkel et al. BMC Bioinformatics (2017) 18:219

Page 2 of 2

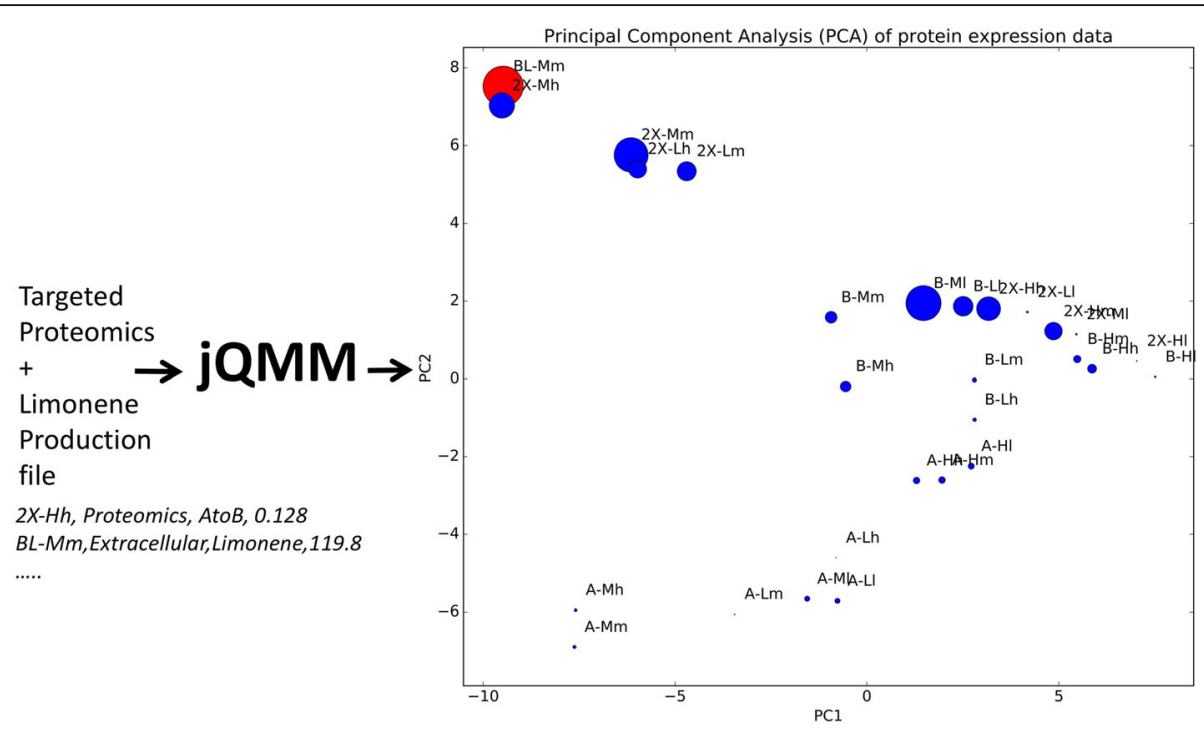

Fig. 7 Principal component analysis (PCA) of protein expression data 